Review

\title{
Online Participatory Journalism: A Systematic Literature Review
}

\author{
Katherine M. Engelke \\ Department of Communication, University of Münster, 48143 Münster, Germany; E-Mail: k.engelke@uni-muenster.de
}

Submitted: 30 May 2019 | Accepted: 3 October 2019 | Published: 17 December 2019

\begin{abstract}
This article presents a systematic literature review of 378 studies (1997-2017) on online participatory journalism, i.e., audience participation in the professional news production process. Participation can challenge established understandings of journalism and affect the relationship between journalists and audience members as peripheral actors due to the increasingly blurred boundaries between these actors and the renegotiation of authority and power. The review captures research practices regarding the theoretical, conceptual and empirical approach as well as results pertaining to the impact participation has on the journalist-audience relationship and is both interdisciplinary and global in nature. The results show that research mostly focuses on journalism in Europe and North America and examines participation in the interpretation stage rather than in the formation or dissemination stage of the news production process. Longitudinal and comparative studies, examinations of regional and local participation, in-depth audience studies as well as analyses of participation in all three production stages are rare. 121 studies explicitly deal with participation's impact on the journalist-audience relationship and produce conflicting results: $51 \%$ see journalists retaining control over news production process; $42 \%$ see shared power; and 7\% see mixed results. Notably, power structures differ depending on the examined world region, production stage, and actor perspective. The review illustrates the status quo of research practices as well as the role the audience as peripheral actors play in the news production process and concludes with five observations about the field as well as future avenues to close identified research gaps.
\end{abstract}

\section{Keywords}

audience; boundary work; digitalization; journalism; participatory journalism; online; news

\section{Issue}

This review is part of the issue "Peripheral Actors in Journalism: Agents of Change in Journalism Culture and Practice" edited by Avery E. Holton (University of Utah, USA), Valerie Belair-Gagnon (University of Minnesota-Twin Cities, USA), and Oscar Westlund (Oslo Metropolitan University, Norway / Volda University College, Norway / University of Gothenburg, Sweden).

(C) 2019 by the author; licensee Cogitatio (Lisbon, Portugal). This article is licensed under a Creative Commons Attribution 4.0 International License (CC BY).

\section{Introduction}

This article focuses on online participatory journalism as a particular way in which audience members as peripheral actors contribute to journalism and presents a systematic literature review of research in this field. Participatory journalism is understood here as audience participation in the news production process within professional journalistic contexts (Abbott, 2017; Borger, 2016; Borger, van Hoof, Costera Meijer, \& Sanders, 2013; Nip, 2006; Singer et al., 2011; Westlund \& Ekström, 2018). Treating journalism as a profession is not unproblematic or even uncontested and conceptualizations thereof differ (Carlson, 2017). We follow Borger's (2016) elaborations on the professional model and its parameters: Professional journal- istic contexts are those in which journalists work abiding by journalistic norms and values, with journalistic degrees or training, for a professional news organization and with payment for their work. While audience participation in professional journalism far predates the digital age (Lee \& Tandoc, 2017), it has become faster, cheaper, more automatized, more inclusive, and more multifaceted due to digitalization (Hermida, 2012; Lee \& Tandoc, 2017; Lewis, 2012), which is why the focus of this article lies specifically on online participation.

The audience's involvement can challenge established understandings of journalism and its producers. While participating members of the audience can still be understood as (one of various groups of) strangers and thus peripheral actors to journalism (Holton \& Belair- 
Gagnon, 2018), they play a role in the professional news production process. This affects boundaries in the relationship between journalists and their audience, which are becoming increasingly blurred as journalistic authority as well as control and power in the news production process are being renegotiated (Carlson, 2017; Deuze, Bruns, \& Neuberger, 2007; Domingo et al., 2008; Lewis \& Molyneux, 2018).

In examining participatory journalism (hereafter, the term is used to describe online participation), scholars have brought forth a plethora of studies that have come to conflicting findings regarding the relationship between journalists and the audience, with some indicating continuity in journalistic power and others indicating a change towards shared power. By synthesizing pertinent studies, this literature review strives to provide clarity regarding and possible explanations for these conflicting findings. More fundamentally, it further aims to generate a comprehensive overview of the theoretical, conceptual, and empirical approaches used to examine participatory journalism. Knowledge about how, in which contexts and with which results regarding its impact on the journalist-audience relationship research on participatory journalism is conducted can contribute insights on and a better understanding of the (more or less powerful) role peripheral actors play in the news production process. At the same time, the analysis can establish a broader basis for future research on participatory journalism and map out new directions for future studies based on disclosed research gaps.

\section{Audience Participation in the Professional News Production Process}

The term "participatory journalism" is used inconsistently and interchangeably with other terms within the literature (Abbott, 2017; Hermida, 2011; Nip, 2006; Singer et al., 2011). This article's understanding of participatory journalism therefore needs to be elaborated on more closely in order to identify specific forms and the corresponding terminology used for them (see Section 2.1). However, we first differentiate participatory journalism from the related but nevertheless distinct concept with which it most often is conflated: citizen journalism. While the term participatory journalism-as understood here-delineates audience participation in the professional news production process, the term citizen journalism is most often understood to describe autonomous audience production of news without professional involvement (Abbott, 2017; Nip, 2006). Interchangeable use continues despite this differentiation, which has consequences for the methodological approach to the systematic review and is therefore discussed again below.

\subsection{Developing a Taxonomy of Audience Participation}

Scholars have used different stages of the news production process to categorize, describe and analyze forms of participation. For example, Domingo et al. (2008) andin later work developed from Domingo et al. (2008)Hermida (2011) conceptualize the following stages: access/observation; selection/filtering; processing/editing; distribution; and interpretation. Based on this previous conceptualization, we distinguish three stages of the professional news production process: (1) formation; (2) dissemination; and (3) interpretation of news. Online audience participation can be a part of the news production process in each stage and take on various forms (Table 1 ).

\subsubsection{Stage 1: Formation}

In the first stage, audience participation can take on six forms. First, the audience can finance journalistic platforms, projects, start-ups, or the journalistic coverage of certain issues via crowdfunding (Jian \& Usher, 2014; Malik \& Shapiro, 2017). The audience can furthermore influence the journalists' content selection: On the one hand, ideas and topics for news are taken directly from qualitative audience contributions found in user-generated content (UGC), which journalists can scrape from the internet, receive without solicitation or attain by inviting users to contribute ideas (Ahva, 2017; Domingo et al., 2008; Santana, 2011). On the other hand, journalists' content selection is guided by quantitative insights from audience metrics and web analytics (Anderson, 2011; Lee \& Tandoc, 2017) or audience polls (Lawrence, Radcliffe, \& Schmidt, 2018; Netzer, Tenenboim-Weinblatt, \& Shifman, 2014), which indicate the popularity of certain news stories and topics. Moreover, the audience can contribute actual content: In order to supplement their professional reporting, journalists draw from UGC, for example in the form of pictures and videos (Deuze et al., 2007; Hellmueller \& Li, 2015; Hermida, 2012; Karlsson, 2011; Paulussen \& Ugille, 2008). Sometimes, journalists use content gained via crowdsourcing, such as information gathered or even analyzed by the audience (Aitamurto, 2016; Hermida, 2011; Malik \& Shapiro, 2017). Finally, members of the audience can be involved in the writing, editing and revision process (Ahva, 2017; Deuze et al., 2007; Hellmueller \& Li, 2015; Netzer et al., 2014) or even write entire news pieces themselves that are then published in professional contexts (Ahva, 2017; Deuze et al., 2007; Hermida, 2011; Karlsson, 2010; Netzer et al., 2014).

\subsubsection{Stage 2: Dissemination}

In the second stage, the audience can participate in two forms. First, the audience can enhance a news piece's prominence by clicking, reading, liking, rating, recommending, sharing and/or commenting on it on the news site itself. The thus aggregated data can cause these news pieces to "go up" on the website or appear as "trending," "most liked," "most viewed," "most commented," "most shared," "highly rated," or similarly labeled (Domingo et al., 2008; Hermida, 2011; Lee \& 
Tandoc, 2017; Netzer et al., 2014). Second and likewise, the audience can also enhance a news piece's prominence by clicking, reading, liking, rating, recommending, sharing and/or commenting on it on external platforms (e.g., in social media and e-mail) and thus draw attention to the news piece (Almgren \& Olsson, 2016; Hermida, 2012; Larsson, 2018).

\subsubsection{Stage 3: Interpretation}

In the third stage, there are four forms of audience participation. Audience members can partake in polls and quizzes about specific news pieces or general public affairs information covered in the news and thus check their comprehension of the news piece or their public affairs knowledge via interaction (Scacco, Muddimann, \& Stroud, 2016). The audience can provide journalists with qualitative feedback on their work (e.g., in comments, blogs or via e-mail) by pointing out mistakes, making corrections, and voicing general criticism or by expressing praise (Heise, Loosen, Reimer, \& Schmidt, 2014; Karlsson, 2010, 2011; Lawrence et al., 2018; Lee \& Tandoc, 2017). Audience metrics and web analytics can constitute a form of quantitative feedback (Duffy, Ling, \& Tandoc, 2018). Finally, this stage encompasses discussing the news in the form of discourse, debates, and interactivity between the audience and the journalistic content, between the audience and journalists, or between various audience members themselves (Deuze et al., 2007; Domingo et al., 2008; Heise et al., 2014; Hille \& Bakker, 2014; Karlsson, 2010, 2011; Santana, 2011; Swart, Peters, \& Broersma, 2019). Just like participation in the dissemination stage, participation in the interpretation stage takes place both within professional news sites, namely in comment fields, discussion forums, chats, blogs, or polls (e.g., Domingo et al., 2008) and outside of professional news sites, namely via e-mail as well as in comments, groups, or thought pieces in social media (e.g., Swart et al., 2019).
While this study's understanding of participatory journalism is narrow regarding the professional context of audience participation-and thus distinct from the concept of citizen journalism-in two other ways, it is broad: First, regarding the degree of involvement (see also, e.g., Netzer et al., 2014), since both more passive, low-involvement types such as reading news comments and more active, high-involvement types such as writing entire news pieces are of interest, and second, with regard to the platform on which participation takes place, with both the news media's own platforms and external platforms such as social media being included (see also Westlund \& Ekström, 2018).

Furthermore, the focus on online participation does not exclude an offline component. Malik and Shapiro (2017, p. 15) describe the border between digital and analogue journalism as "porous," which also applies to participatory journalism, where offline and online participation are not mutually exclusive. Thus, studies that examine participation in both online and offline environments are relevant to the literature review, while studies focusing exclusively on offline participation (e.g., letters to the editor) are excluded.

\subsection{Impact of Audience Participation on the Journalist-Audience Relationship}

Participation's impact on the journalist-audience relationship is often examined within the larger context of journalistic boundaries (Lewis, 2012). As Table 1 illustrates, there has been a shift in the understanding of journalism and its producers in that the formerly established boundaries between journalists as producers and the audience as consumers of journalism have become blurred in all three stages of the news production process. This, in turn, pertains directly to questions of power and control (Lewis \& Molyneux, 2018) and to questions regarding journalistic authority as "a contingent relationship in which certain actors come to pos-

Table 1. Taxonomy of forms of audience participation in the news production process.

\begin{tabular}{ll}
\hline Stages & Forms of participation \\
\hline Formation & - Audience finances news via crowdfunding \\
& - Audience influences content selection qualitatively \\
& - Audience influences content selection quantitatively \\
& - Audience content supplements professional reporting \\
& - Audience produces entire news pieces \\
\hline Dissemination & - Audience enhances prominence of news on journalistic sites \\
& - Audience enhances prominence of news on external platforms \\
\hline Interpretation & - Audience checks comprehension via interaction \\
& - Audience gives journalists qualitative feedback \\
& - Audience gives journalists quantitative feedback
\end{tabular}

Note: The distinction of the three stages is based on the stages of the news production process by Domingo et al. (2008) and Hermida (2011). 
sess a right to create legitimate discursive knowledge about events in the world for others" (Carlson, 2017, p. 13). Focusing on the journalist-audience relationship, the audience may be transitioning from solely being "others" to also joining journalists as "certain actors" (Carlson, 2017, p. 13).

Strangers or peripheral actors to journalism are particular drivers of journalistic change (Holton \& BelairGagnon, 2018) and the participating audience is no exception. But despite the general consensus that participation has led to changes, the specific extent of participatory journalism's impact on the boundaries of journalism is disputed. Broadly speaking, two stances seem to have emerged on this issue, one more reflective of change, the other more reflective of continuity in journalism (see also Carlson \& Lewis, 2019).

The first stance is that audience participation causes a fundamental "shift from a top-down lecture to an open conversation" (Paulussen \& Ugille, 2008, p. 25) in the journalist-audience relationship. This stance therefore describes a situation of shared power, in which the audience and journalists act as peer-level collaborators (e.g., Aitamurto, 2016; Anderson, 2011; Jian \& Usher, 2014). The second stance is that audience participation has a less fundamental impact: Journalists allow audience participation to a limited extent, but retain both power and their traditional gatekeeping roles (e.g., Domingo et al., 2008; Heise et al., 2014; Lawrence et al., 2018). This continuous imbalance of power has also been ascribed to journalists' wanting to avoid problematic contributions in the form of so-called "dark participation," which seem to be particularly prevalent on external platforms (Quandt, 2018), or the audience simply not making use of the possible forms of participation (Larsson, 2011).

\subsection{Research Questions}

In order to provide a comprehensive and systematic analysis of how, in which contexts, and with which results regarding its impact on the journalist-audience relationship research on participatory journalism is conducted, two main research questions are posed:

- RQ1: Which research practices can be identified regarding the theoretical, conceptual, and empirical approach?

- RQ2: What results regarding the impact of participatory journalism on the relationship between journalists and the audience can be discerned?

\section{Methodological Approach}

Systematic reviews synthesize primary scholarship on a specific subject in order to both disclose the status quo and identify research gaps regarding this subject. The systematic strategies for identifying and analyzing relevant studies were developed following established and proven guidelines (Cooper, 1998).
The goal of this study is to conduct an exhaustive analysis of all English-language empirical studies published in peer-reviewed journals that deal specifically and solely with online participatory journalism. Relevant studies were located via a database search in Scopus. A database search was chosen in contrast to focusing on specific journals because the boundaries of journalism research are not always clear-cut (Wahl-Jorgensen \& Hanitzsch, 2009). Concentrating on selected communication or journalism journals would limit the review's comprehensiveness. Besides achieving an interdisciplinary scope, a database search includes minor journals with a low impact factor. Thus, its scope is more global than focusing on North American- and European-dominated (Wahl-Jorgensen \& Hanitzsch, 2009) major and highranking journals.

As previously mentioned, research on participatory journalism is often conducted under other terms such as "citizen journalism" or "UGC" and research conducted under the term "participatory journalism" may deal with other concepts (Abbott, 2017; Hermida, 2011; Nip, 2006; Singer et al., 2011). Simply using the term "participatory journalism" to uncover relevant literature would therefore be insufficient. Hence, a scoping study was conducted in order to develop appropriate search terms from previous literature and to achieve content validity. For this, we drew upon 42 publications (see Appendix) that fulfill the defined inclusion criteria(1) English-language, (2) published in a peer-reviewed journal, (3) features an empirical study, (4) deals specifically and solely with online participatory journalismand derived search terms from their keywords. We deliberately included publications without the terms "participation/participatory" in their title, abstract or keywords, publications featuring both low- and high-involvement forms of participation, publications from all three stages of the news production process and both older and more recent publications. The 42 publications comprise 152 unique keywords, which were grouped into the three areas of: (1) news/journalism; (2) forms of audience participation; and (3) digitalization. Based on the most important terms per area, the following search string was applied: "(journalis* OR news OR newsroom* OR newspaper*) AND (analytics OR audience* OR blog* OR citizen* OR comment* OR crowd* OR engagement OR interactivity OR metrics OR reader OR sharing OR participat* OR reciproc* OR user) AND (digital* OR online OR web*)".

The search was conducted in the titles, abstracts, and keywords of all Scopus publications up to and including 2017 and limited to English-language journal articles (including in press), leading to 4259 potentially relevant publications. Two coders examined the titles and abstracts of these publications as to whether they fulfilled the inclusion criteria, resulting in 766 potentially relevant publications. Full articles could be obtained for 760 publications. The author then examined all full articles, resulting in 372 relevant publications. In this step, publications were most often excluded because they dealt with citizen 
journalism or with broader aspects of digital journalism such as journalists' general social media use. Six publications included two studies on participatory journalism, bringing the total to 378 reviewed studies.

The deductively developed codebook contained both quantitative and openly coded qualitative variables related to information on: (1) the publication and its author(s); (2) the study and the examined stage(s) of participation; (3) the theoretical approach; (4) the conceptual approach, including forms and types of participation; (5) the empirical approach, comprising both research designs and settings; and (6) the results regarding the journalist-audience relationship. Following a pretest, some minor adjustments were made. Two researchers (Holsti $=.94$ ) performed the coding. Regarding the content variables, agreement was highest for the research design variables (Holsti $=.97$ ) and lowest for the results (Holsti $=.75$ ).

\section{Results}

The number of publications on participatory journalism $(\mathrm{N}=372$ ) has increased significantly: $1 \%$ of publications stem from 1997-2002; 2\% from 2003-2007; $23 \%$ from 2008-2012; and 74\% from 2013-2017, with a peak of 67 publications in 2015 . For all publications, the year of the initial publication was coded, even if the year of an advance online publication differs from the year of the subsequent issue publication. The publications are published in 148 different journals. For each journal, the subject areas listed in SCImago (2019) were used to determine the served disciplines, while self-descriptions on the journals' websites were drawn upon for those not listed in SClmago (Table 2).

Of the 148 journals, 69 are communication journals and contain $71 \%$ of all publications. Communication jour- nals were identified by their being listed in the subject category "Communication" in SCImago (2019). We follow Carlson, Robinson, Lewis, and Berkowitz's (2018) classification of journalism studies as a subdiscipline of communication and therefore searched for journalism journals within the communication journals. Ten journalism journals were identified manually by their titles including the keyword "journalism," "press" or "newspaper." They contain $34 \%$ of all publications. The dominant journals are Journalism Practice (31 publications), Digital Journalism (28), New Media \& Society (19), Journalism (17) and Journalism Studies (16). For the 111 publications in these top five journals, we checked the relevance of special issues and found that 30 publications stem from 17 such issues, although New Media \& Society contains none. Notably, nine of these special issues-containing twelve publications-emerged from the biennial "Future of Journalism Conference" in Cardiff. Besides this, three special issues-containing ten publications-deal specifically with participatory journalism and/or the related concept of citizen journalism. Returning to the entire corpus of 372 publications, we find that most (teams of) authors are North American (42\%) or European (41\%). Most first authors are from the US (39\%), with the UK (13\%) and Germany (5\%) ranking a distant second and third. Over time, there is an increase of publications from noncommunication journals, a decline of (teams of) authors from North America, an increase of (teams of) authors from Europe, and a small increase of author teams from multiple regions. Only $8 \%$ of publications empirically focus on offline in addition to online participation.

RQ1 deals with the research practices of the reviewed studies $(\mathrm{N}=378)$. Changes over time are pointed out when present. $94 \%$ of the studies have one or more theoretical contexts. The considerable number of more than 400 openly coded contexts corresponds to an analy-

Table 2. Disciplines of the journals.

\begin{tabular}{lrr}
\hline Discipline & $\mathbf{n}$ & \% \\
\hline Social Sciences & 122 & 82 \\
Arts and Humanities & 32 & 22 \\
Computer Science & 28 & 19 \\
Psychology & 15 & 10 \\
Medicine & 12 & 8 \\
Business, Management and Accounting & 9 & 6 \\
Engineering & 8 & 5 \\
Environmental Science & 5 & 3 \\
Biochemistry, Genetics and Molecular Biology & 2 & 1 \\
Decision Sciences & 2 & 1 \\
Economics, Econometrics and Finance & 2 & 1 \\
Agriculture and Biological Sciences & 1 & 1 \\
Earth and Planetary Sciences & 1 & 1 \\
Mathematics & 1 & 1 \\
Multidisciplinary & 1 & 1 \\
\hline Notes: $N$ (148. Coding of multiple disciplines per journal pas possible. Disciplines & \\
\hline
\end{tabular}

Notes: $\mathrm{N}=148$. Coding of multiple disciplines per journal was possible. Disciplines were determined using the subject areas listed in SCImago (2019). 
sis of disciplinary perspectives and theories in Journalism and Journalism Studies by Steensen and Ahva (2015), who found theoretical approaches in journalism studies to be "characterized by the "long tail'" (p. 12) with a few popular and a plethora of more seldom-referred to theories. Only seven contexts are used in more than $5 \%$ of all studies: public sphere $(13 \%)$, gatekeeping $(9 \%)$, interactivity $(8 \%)$, deliberation (7\%), framing $(6 \%)$, citizen journalism (6\%), and participatory journalism (6\%).

Regarding the conceptual approach, only $31 \%$ of all studies explicitly address participatory journalism in their title, keywords and/or abstracts. The three stages of the news production process are not focused on equally: $30 \%$ of the studies deal with the formation, $23 \%$ with the dissemination, and $77 \%$ with the interpretation of news. The majority of studies focus on just one stage $(77 \%)$ as opposed to two (16\%) or all three stages (7\%). The examined stages are reflected in the examined forms (Table 3), with audience involvement in the discussion of news (74\%) as the by far most often examined form. Over time, the number of examined forms has increased: While period one (1997-2002) features only two forms, period two (2003-2007) already features seven forms and the last two periods feature all twelve forms. The distribution in Table 3 is reflective of user comments being the most prevalent and one of the oldest participation types (Ziegele, 2019) as well as of the emergence of new participatory forms over time.

Turning to the empirical approach and specifically the research design, multi-method studies (25\%) are less common than single-method studies (75\%). Most studies are quantitative $(50 \%)$, followed by qualitative $(37 \%)$ and mixed methods (13\%). Content analyses are employed more often (66\%) than interviews (44\%)-comprising both surveys and in-depth interviews-and observations (6\%). Only $11 \%$ of all studies employ longitudinal and only $12 \%$ employ experimental designs in at least one of the applied methods. The dominance of content analyses and interviews-especially surveys-and quantitative approaches in general reflects the results of previous reviews on issues that are aspects of or related to participatory journalism (e.g., Kümpel, Karnowski, \& Keyling, 2015; Naab \& Sehl, 2017).

Regarding the settings, a clear focus on European (39\%) and North American (38\%) journalism emerges (Table 4). Notably, the North American focus decreases while the European focus increases from period three (2008-2012) to four (2013-2017). Due to the earlier onset of an economic crisis in legacy media in the US (Nielsen, 2016), participation may have played a larger role for economic-strategic reasons-i.e., to acquire free content, build audience loyalty, optimize con-

Table 3. Forms of participation examined in the studies.

\begin{tabular}{|c|c|c|c|}
\hline Form & Stage & $\mathbf{n}$ & $\%$ \\
\hline Audience involved in discussion of news & Interpretation & 278 & 74 \\
\hline Audience enhances prominence of news on external platforms & Dissemination & 64 & 17 \\
\hline Audience content supplements professional reporting & Formation & 63 & 17 \\
\hline Audience gives journalists qualitative feedback & Interpretation & 47 & 12 \\
\hline Audience enhances prominence of news on journalistic sites & Dissemination & 41 & 11 \\
\hline Audience produces entire news pieces & Formation & 39 & 10 \\
\hline Audience influences content selection qualitatively & Formation & 33 & 9 \\
\hline Audience influences content selection quantitatively & Formation & 21 & 6 \\
\hline Audience gives journalists quantitative feedback & Interpretation & 12 & 3 \\
\hline Audience checks comprehension via interaction & Interpretation & 11 & 3 \\
\hline Audience finances news via crowdfunding & Formation & 11 & 3 \\
\hline Audience involved in writing, editing and revision & Formation & 7 & 2 \\
\hline
\end{tabular}

Notes: $\mathrm{N}=378$. Coding of multiple forms per study was possible. The distinction of the three stages is based on the stages of the news production process by Domingo et al. (2008) and Hermida (2011).

Table 4. Regional focus of studies.

\begin{tabular}{lrr}
\hline Region & $\mathbf{n}$ & \% \\
\hline Europe & 146 & 39 \\
North America & 145 & 38 \\
Asia & 31 & 8 \\
Multiple regions & 23 & 6 \\
Africa & 12 & 3 \\
Oceania & 9 & 2 \\
South America & 6 & 2 \\
No information provided/unclear & 6 & 2 \\
\hline
\end{tabular}

Note: $\mathrm{N}=378$. 
tent selection, and generate traffic (Anderson \& Revers, 2018; Batsell, 2015; Borger et al., 2013; Holton \& BelairGagnon, 2018)-in North American before it did in European journalism. The shift in focus-and the earlier presented shift in authorship-could also be a reflection of the more general trend Hanusch and Vos (2019) find in their longitudinal review of comparative studies of journalism: "The pole of power is shifting from the US to Europe" (p. 19). 12\% of all studies are comparative, but only $6 \%$ examine countries from multiple world regions, which reflects the practical challenges of comparative research. Participation is researched most often in the US (41\%), the UK (16\%), and Germany (8\%). This Western dominance-especially the AngloAmerican dominance-also emerges in other reviews in this area (e.g., Kümpel et al., 2015) and in (comparative) journalism studies in general (Hanusch \& Vos, 2019; Wahl-Jorgensen \& Hanitzsch, 2009). Studies of participatory journalism mostly focus on the national level (63\%), followed by multiple levels $(11 \%)$, the local level $(8 \%)$, and the regional level (4\%), which mirrors journalism studies' institutionalized focus on "prestigious, elite, and well resourced newsrooms" (Wahl-Jorgensen, 2019, p. 165).

Looking at the perspective from which participatory journalism is examined, the audience perspective (33\%) outweighs the journalist perspective (19\%) and both perspectives (7\%), although $42 \%$ of all studies feature no perspective. While this seems to indicate that much more is known about audience views than journalists' views, a closer look at the employed methods tells a different story. Of the 70 studies from the journalist perspective, 52 ( $14 \%$ overall) conduct qualitative interviews and thus provide in-depth insights into journalists' views on participation. Of the 124 studies from the audience perspective, only twelve (3\% overall) conduct qualitative interviews with audience members. The majority of these twelve studies interview highly involved audience members-most often active contributors of news pieces but also members active as commenters or in crowdsourcing-while only two studies focus on lowly involved audience members. Furthermore, 42 of the 46 experimental studies are from the audience perspective. Notably, only $6 \%$ of the studies focus on a specific relationship, i.e., examine participation from the view of both journalists and their specific (connected) audience.

RQ2 focuses on the results regarding the impact of participatory journalism on the journalist-audience relationship. The impact is only dealt with in $32 \%$ of all examined studies. In these studies $(N=121)$, power over the news production process is most often seen to remain with the journalists (51\%). Less often, power is seen as shared (42\%). $7 \%$ of the studies come to mixed results. This Janus-faced and fairly balanced picture mirrors the two stances on power described above, although notable differences and stronger imbalances emerge depending on the context (Table 5): Power is predominantly seen as shared in North America but as remaining with the journalists in Europe. Journalists are perceived mostly as remaining in power in the formation and interpretation stages, while studies in the dissemination stage predominantly see shared power. Finally, studies from the journalist and audience perspective mostly see shared power, albeit with journalists to a lesser extent than the audience.

\section{Discussion and Conclusion}

Based on the results, five observations can be made about the field of participatory journalism in general and the results regarding the journalist-audience relationship in particular.

\subsection{Participatory Journalism Is an Interdisciplinary Field}

While clearly dominated by communication and journalism studies, the large and growing number of publications in non-communication journals indicates an increasing research interest in audience participation outside of journalism and even communication studies. This

Table 5. Differences in the impact of audience participation on the journalist-audience relationship by context.

\begin{tabular}{llccc}
\hline & & \multicolumn{2}{c}{ Impact on the journalist-audience relationship } \\
\cline { 3 - 5 } & Context & $\begin{array}{c}\text { Shared power } \\
\text { (in \%) }\end{array}$ & $\begin{array}{c}\text { Power remains with journalists } \\
\text { (in \%) }\end{array}$ & $\begin{array}{c}\text { Mixed results } \\
\text { (in \%) }\end{array}$ \\
\hline Regional focus & North America $(n=45)$ & 56 & 40 & 4 \\
& Europe $(n=53)$ & 28 & 66 & 6 \\
\hline Stage & Formation $(n=81)$ & 40 & 54 & 6 \\
& Dissemination $(n=38)$ & 55 & 55 & 3 \\
\hline Perspective & Interpretation $(n=78)$ & 39 & 43 & 6 \\
& Journalist $(n=49)$ & 49 & 30 & 8 \\
\hline & Audience $(n=20)$ & 60 & 51 & 7 \\
\hline
\end{tabular}

Notes: $\mathrm{N}=121$. Percentages are given for easier comparability despite the context subsets' small sizes. The distinction of the three stages is based on the stages of the news production process by Domingo et al. (2008) and Hermida (2011). 
is underlined by the fact that journals publishing research on participatory journalism serve a wide variety of disciplines despite being strongly rooted in social sciences (Table 2), just like (digital) journalism studies in general (Steensen \& Ahva, 2015; Steensen, Larsen, Hågvar, \& Fonn, 2019).

\subsection{Participatory Journalism Is a Growing Field}

Participatory journalism's growth is not only illustrated by the increase in publications, but becomes especially apparent in comparison to the overall output in journalism studies: While Steensen and Ahva (2015) saw a significant increase of articles published in Journalism Studies and Journalism from 378 in 2000-2006 to 652 in $2007-2013$, the number of publications on participatory journalism found in this study increased from 8 in 1997-2006 to 138 in 2007-2013. Besides increasing non-communication interest, possible explanations for this growth are the emergence of relevant journals (Journalism Practice, Digital Journalism) as well as the documented increase in forms and types of participation over time. The research interest in capturing and understanding such new objects (see also Carlson \& Lewis, 2019) may be a reason why longitudinal studies are rare. Furthermore, results for the top five journals indicate that while special issues certainly are an important driver of research on participatory journalism, most studies are published independently from such calls. This shows that there is a wide scholarly interest in the topic that goes beyond special issues - often resulting from themed conferences and workshops or specific events-and that may explain its increasing prominence.

\subsection{Participatory Journalism Is a Fragmented Field}

The increase in examined forms of participation indicates more and more specific research interests, while the multitude of non-communication journals and theoretical contexts mirrors the diverse backgrounds against which research is being conducted. Considering the most common theoretical contexts, for example, some scholars are interested in participation's democratic potential or lack thereof (e.g., public sphere, interactivity, deliberation) and others focus on questions of selection (e.g., gatekeeping, framing). Even within contexts, different stances may be driving research (regarding research in democratic contexts, see, e.g., Anderson \& Revers, 2018 , for a reconstruction of the evolution of both optimistic and pessimistic views on participation). It seems that participatory journalism is predominantly explored in light of these specific interests that even range into the natural sciences (Table 2). This could be an explanation for why so few studies explicitly address participatory journalism, why research seldom considers more than one stage of participation, and why so few studies focus on overarching questions of power in the journalistaudience relationship.

\subsection{Research on Participatory Journalism Focuses on Journalists' Views and Audiences' (Re)Actions}

The results pertaining to the actor perspective indicate that there may be differently nuanced research aims on the part of scholars when it comes to the actors involved in participatory journalism: While scholars seem to be interested in journalists' views on participation, their interest in the audience appears to focus more on their actions in participatory formats (e.g., the amount and content of user comments) or on their reactions to participation (e.g., influence of certain kinds of comments on the audience). Another reason for the dominance of in-depth views from journalists may be easier accessibility of journalists for interviews due to existing contacts and quick identification of relevant interview partners. The fact that most interviewed audience members are highly involved indicates that easy identification and accessibility could also play a role here. The lack of research on specific relationships from both perspectives may involve both accessibility and feasibility issues, since gaining access to and examining one actor group alone is less laborious and costly than doing so with two connected groups. While the field has therefore generated in-depth knowledge on journalists' views, in-depth insights into (connected) audience views are scarce despite the extensive focus on their perspective.

\subsection{The Impact of Audience Participation on the Journalist-Audience Relationship Is Nuanced}

While the Janus-faced picture regarding power over the news production process is unsurprising, the review reveals interesting insights regarding the context. This shows that while participatory journalism is a global and pervasive phenomenon, its impact on the boundaries of journalism is nuanced: Table 5 illustrates that the fairly balanced overall impact disappears and notable differences as well as stronger imbalances (apart from the journalistic perspective) emerge when specific contexts are considered. What are possible explanations for the differences? The audience may be seen as more powerful in North America than in Europe due to the early onset of an economic crisis in US legacy media (Nielsen, 2016) and the consequent need for participation for economic-strategic reasons (Anderson \& Revers, 2018; Batsell, 2015; Borger et al., 2013; Holton \& Belair-Gagnon, 2018). While Borger et al. (2013) note that participation is nevertheless "kept at bay in terms of participants being co-decision makers or co-storytellers, positions that challenge journalists' authority" (p. 129), the North American audience's more powerful position could be due to its involvement dating back further than in Europe, possibly allowing it to acquire a more sustained role in the news production process over time. This may be driven especially by participation in the dissemination stage. That power is predominantly seen as shared here in contrast to the formation and interpretation stages indicates that 
journalists may value help in having their work spread and in increasing its prominence and thus traffic (see Borger et al., 2013) but want to retain control over the selection and understanding of their work. Journalists have long been hesitant to allow participation in the formation stage (e.g., Domingo et al., 2008; Lawrence et al., 2018), but the findings regarding the interpretation stage may be more nuanced. Two possible reasons for hesitance on the part of journalists to share power in this stage may be the costs of comment moderation for newsrooms (e.g., Hille \& Bakker, 2014) and, as already discussed briefly above, fears of "dark participation" (Quandt, 2018). Recent trends of restricting comment opportunities for audiences after years of expanding comment sections (Ziegele, 2019) illustrate journalists' retention of power. That studies from the audience perspective see shared power much more often than studies from the journalist perspective could be explained by the fact that the audience may have only little understanding of the professional news production process and therefore be unaware of all the places journalists (can and do) limit the impact of audience participation. Journalists are certainly more aware of this process and may thus see the power of the audience as less pronounced. Furthermore, the strong influence of the context could be seen as a reflection of the fragmentation of the field: The differences mirror the diverse theoretical contexts and research interests scholars bring to the table, the manifold different forms that are examined and the various empirical approaches and settings that are employed. Overall, the results regarding RQ2 indicate that generalized statements on participatory journalism's impact on the journalisticaudience relationship should only be made with caution. But maybe the takeaway of RQ2 should not only be that context is vital, but-more fundamentally - that the audience plays a (more or less powerful) role in the news production process across various contexts, while appearing particularly powerful in North America, in the dissemination stage and from the audience perspective. In order to better understand where journalistic authority is changing and peripheral actors are becoming central, more research on the contexts of participation is needed-as well as comprehensive overviews and comparisons of the influence of these different contexts. Overall, the results indicate that while participation certainly influences the power dynamics, it does not necessitate a radical reconceptualization of journalism and its producers, but rather a broader and more nuanced understanding thereof which reflects both the continuity and change within the boundaries of journalism.

Based on the results and identified research gaps, we list four important aspects for future research. While the list is certainly not comprehensive, it serves as a starting point for further inquiries into participatory journalism.

- The field needs more longitudinal studies (e.g., Nelson \& Tandoc, 2019). While longitudinal stud- ies face both methodological and organizational challenges, they are crucial in illustrating both continuity and change (Carlson \& Lewis, 2019) over time. Furthermore, longitudinal comparative research allows researchers to capture similarities and differences over time as well as the influence of greater transformation processes (Esser \& Hanitzsch, 2012). In light of the field's growthdriven partially by an increasing number of participation forms - a reflection and differentiation of both sustained and fleeting trends as well as of their causes seems to hold rich potential and may help put the manifold cross-sectional results into better perspective.

- The results identify a need for (cross-regionally) comparative (e.g., Netzer et al., 2014) and holistic research-with regard to the three production stages (e.g., Domingo et al., 2008) and the actor perspectives (e.g., Heise et al., 2014)-that captures both opportunities for participation and its impact on the journalist-audience relationship. While the inclusion of further context factors would be welcome, the review shows the regional focus, stage, and perspective to be three of the most important factors when it comes to differences. The study's results (Table 3, Table 4) indicate which forms of participation and which world regions have been somewhat neglected so far and the research of which may therefore contribute to a more comprehensive understanding of participatory journalism and its impact. The uncovered differences (Table 5) illustrate the importance not only of a holistic but also of a nuanced approach: Researches should bear in mind the differences and take possible explanations-as discussed: economic developments, journalists' reluctance to share power, and the audience's understanding of the news production process-into account when designing their research instruments.

- Research should move away from the focus on elites (e.g., Canter, 2013; Mitchelstein, 2011): World regions besides North America and Europe (Table 4) as well as the local and regional level have been particularly neglected. Not only do local and regional media appear to be more open to participation (Lewis, Holton, \& Coddington, 2014), these levels have also been hit harder by declines (Wahl-Jorgensen, 2019) and thus may more likely turn to participatory journalism to counteract economic challenges. Research in this area may therefore lead to interesting insights that differ from national media.

- Studies focusing on both actor perspectives in specific relationships (e.g., Wenzel, 2019) could provide a more complete and accurate picture of participation's impact on the relationship than just capturing one perspective. Specifically, the results show that more qualitative audience re- 
search (e.g., Ahva, 2017) is needed in order to better understand its views on participatory journalism and to provide more insights on the characteristics and motivations of those peripheral actors that are participating in the news production process. Importantly, qualitative efforts should not only focus on active, highly involved actors, but also on previously less examined passive, lowly involved or even non-participating actors, since research has shown that this reflects a large portion of the audience (e.g., Borger et al., 2013).

The review's results and discussion must be seen in light of several limitations. First, the review is only exhaustive for the inclusion criteria outlined in Section 3 and the journals included in Scopus. Second, the body of literature reviewed depends strongly on our understanding of participatory journalism. A different definitione.g., one including citizen journalism-would most likely lead to a different picture than the one painted here (see Abbott, 2017, for differences in scholarship on participatory and citizen journalism). Third, scoping studies are not infallible and relevant publications may have been missed despite our best efforts to develop a comprehensive search string. Fourth, including non-English publications as well as further source types besides journalse.g., such seminal publications as Singer et al. (2011), which is the most cited book in work published in Digital Journalism (Steensen et al., 2019) - may lead to different results. Fifth, online participatory journalism is a moving target. Thus, the results of and insights based on this review are somewhat preliminary in nature. Finally, it is important to stress that while the review reveals how participatory journalism is examined, this only allows limited conclusions to be drawn on the actual practice of participatory journalism. At the very least, we hope the transparent description of our approach allows potential optimizations or extensions of the review to build upon our work-both the taxonomy (Table 1) and the empirical results-without problem.

In conclusion, this article provides a systematic review of 378 studies on online participatory journalism, revealing the predominant research practices in the field as well as results pertaining to participation's impact on the journalist-audience relationship. It thus advances research on peripheral actors in the form of the participating audience members and their impact on journalism. At the same time, it highlights remaining research gaps and proposes future avenues that aim to further deepen our understanding of who these audience members are, what drives them to participate, and how this participation changes their relationship with professional journalists and power structures in journalism.

\section{Acknowledgments}

The author would like to thank Max Kniesberg for his contribution to the coding process. An earlier version of this article was presented at the 2019 International Communication Association preconference "Engaged Journalism: Bridging Research and Practice" in Washington, DC. The author is grateful to the preconference attendees, to Max Kniesberg and Laura Badura, as well as to the anonymous reviewers and the editors for their helpful feedback on the study and earlier versions of this article. Furthermore, the author acknowledges support from the Open Access Publication Fund of the University of Münster.

\section{Conflict of Interests}

The author declares no conflicts of interest.

\section{References}

Abbott, J. Y. (2017). Tensions in the scholarship on participatory journalism and citizen journalism. Annals of the International Communication Association, 41(3/4), 278-297.

Ahva, L. (2017). How is participation practiced by "in-betweeners" of journalism? Journalism Practice, 11(2/3), 142-159.

Aitamurto, T. (2016). Crowdsourcing as a knowledgesearch method in digital journalism. Digital Journalism, 4(2), 280-297.

Almgren, S., \& Olsson, T. (2016). Commenting, sharing and tweeting news. Nordicom Review, 37(2), 67-81.

Anderson, C. W. (2011). Between creative and quantified audiences: Web metrics and changing patterns of newswork in local US newsrooms. Journalism, 12(5), 550-566.

Anderson, C. W., \& Revers, M. (2018). From counterpower to counter-Pepe: The vagaries of participatory epistemology in a digital age. Media and Communication, 6(4), 24-35.

Batsell, J. (2015). Engaged journalism: Connecting with digitally empowered news audiences. New York, NY: Columbia University Press.

Borger, M. (2016). Participatory journalism: Rethinking journalism in the digital age? Amsterdam: Uitgeverij BoxPress.

Borger, M., van Hoof, A., Costera Meijer, I., \& Sanders, J. (2013). Constructing participatory journalism as a scholarly object. Digital Journalism, 1(1), 117-134.

Canter, L. (2013). The source, the resource and the collaborator: The role of citizen journalism in local UK newspapers. Journalism, 14(8), 1091-1109.

Carlson, M. (2017). Journalistic authority: Legitimating news in the digital era. New York, NY: Columbia University Press.

Carlson, M., \& Lewis, S. C. (2019). Temporal reflexivity in journalism studies: Making sense of change in a more timely fashion. Journalism, 20(5), 642-650.

Carlson, M., Robinson, S., Lewis, S. C., \& Berkowitz, D. A. (2018). Journalism studies and its core commitments: The making of a communication field. Journal of Com- 
munication, 68(1), 6-25.

Cooper, H. (1998). Synthesizing research. Thousand Oaks, CA: SAGE.

Deuze, M., Bruns, A., \& Neuberger, C. (2007). Preparing for an age of participatory news. Journalism Practice, 1(3), 322-338.

Domingo, D., Quandt, T., Heinonen, A., Paulussen, S., Singer, J. B., \& Vujnovic, M. (2008). Participatory journalism practices in the media and beyond. Journalism Practice, 2(3), 326-342.

Duffy, A., Ling, R., \& Tandoc, E. C. (2018). The people have spoken (The bastards?). Journalism Practice, 12(9), 1130-1147.

Esser, F., \& Hanitzsch, T. (2012). On the why and how of comparative inquiry in communication studies. In F. Esser \& T. Hanitzsch (Eds.), Handbook of comparative communication research (pp. 3-22). New York, NY: Routledge.

Hanusch, F., \& Vos, T. P. (2019). Charting the development of a field: A systematic review of comparative studies of journalism. The International Communication Gazette. Advance online publication. https://doi. org/10.1177/1748048518822606

Heise, N., Loosen, W., Reimer, J., \& Schmidt, J.-H. (2014). Including the audience. Journalism Studies, 15(4), 411-430.

Hellmueller, L., \& Li, Y. (2015). Contest over content. Journalism Practice, 9(5), 617-633.

Hermida, A. (2011). Mechanisms of participation. In J. B. Singer, A. Hermida, D. Domingo, A. Heinonen, S. Paulussen, T. Quandt, ... M. Vujnovic (Eds.), Participatory journalism: Guarding open gates at online newspapers (pp. 13-33). Malden, MA: WileyBlackwell.

Hermida, A. (2012). Social journalism: Exploring how social media is shaping journalism. In E. Siapera \& A. Veglis (Eds.), The handbook of global online journalism (pp. 309-328). Malden, MA: Wiley-Blackwell.

Hille, S., \& Bakker, P. (2014). I like news: Searching for the "holy grail" of social media: The use of Facebook by Dutch news media and their audiences. European Journal of Communication, 28(6), 663-680.

Holton, A., \& Belair-Gagnon, V. (2018). Strangers to the game? Interlopers, intralopers, and shifting news production. Media and Communication, 6(4), 70-78.

Jian, L., \& Usher, N. (2014). Crowd-funded journalism. Journal of Computer-Mediated Communication, 19(2), 155-170.

Karlsson, M. (2010). Rituals of transparency. Journalism Studies, 11(4), 535-545.

Karlsson, M. (2011). Flourishing but restrained. Journalism Practice, 5(1), 68-84.

Kümpel, A. S., Karnowski, V., \& Keyling, T. (2015). News sharing in social media: A review of current research on news sharing users, content, and networks. Social Media + Society, 1(2), 1-14.

Larsson, A. O. (2011). Interactive to me-Interactive to you? A study of use and appreciation of interactivity on Swedish newspaper websites. New Media \& Society, 13(7), 1180-1197.

Larsson, A. O. (2018). Diversifying likes. Journalism Practice, 12(3), 326-343.

Lawrence, R. G., Radcliffe, D., \& Schmidt, T. R. (2018). Practicing engagement. Journalism Practice, 12(10), 1220-1240.

Lee, E.-J., \& Tandoc, E. C. (2017). When news meets the audience. Human Communications Research, 43(4), 436-449.

Lewis, S. C. (2012). The tension between professional control and open participation. Information, Communication \& Society, 15(6), 836-866.

Lewis, S. C., Holton, A. E., \& Coddington, M. (2014). Reciprocal journalism. Journalism Practice, 8(2), 229-241.

Lewis, S. C., \& Molyneux, L. (2018). A decade of research on social media and journalism: Assumptions, blind spots, and a way forward. Media and Communication, 6(4), 11-23.

Malik, A., \& Shapiro, I. (2017). What's digital? What's journalism? In B. Franklin \& S. A. Eldridge II (Eds.), The Routledge companion to digital journalism studies (pp. 15-24). New York, NY: Routledge.

Mitchelstein, E. (2011). Catharsis and community: Divergent motivations for audience participation in online newspapers and blogs. International Journal of Communication, 5, 2014-2034.

Naab, T. K., \& Sehl, A. (2017). Studies of user-generated content: A systematic review. Journalism, 18(10), 1256-1273.

Nelson, J. L., \& Tandoc, E. C. (2019). Doing "well” or doing "good": What audience analytics reveal about journalism's competing goals. Journalism Studies, 20(13), 1960-1976.

Netzer, Y., Tenenboim-Weinblatt, K., \& Shifman, L. (2014). The construction of participation in news websites. Journalism Studies, 15(5), 619-631.

Nielsen, R. K. (2016). The many crises of Western journalism: A comparative analysis of economic crises, professional crises, and crises of confidence. In J. C. Alexander, E. B. Breese, \& M. Luengo (Eds.), The crisis of journalism reconsidered (pp. 77-97). New York, NY: Cambridge University Press.

Nip, J. (2006). Exploring the second phase of public journalism. Journalism Studies, 7(2), 212-236.

Paulussen, S., \& Ugille, P. (2008). User generated content in the newsroom: Professional and organisational constraints on participatory journalism. Westminster Papers in Communication and Culture, 5(2), 24-41.

Quandt, T. (2018). Dark participation. Media and Communication, 6(4), 36-48.

Santana, A. D. (2011). Online readers' comments represent new opinion pipeline. Newspaper Research Journal, 32(3), 66-81.

Scacco, J. M., Muddimann, A., \& Stroud, N. J. (2016). The influence of online quizzes on the acquisition of public affairs knowledge. Journal of Information Technology \& Politics, 13(4), 311-325. 
SCImago. (2019). SJR: SCImago Journal \& Country Rank. SClmago. Retrieved from http://www.scimagojr.com

Singer, J. B., Hermida, A., Domingo, D., Heinonen, A., Paulussen, S., Quandt, T., ... Vujnovic, M. (2011). Participatory journalism: Guarding open gates at online newspapers. Malden, MA: Wiley-Blackwell.

Steensen, S., \& Ahva, L. (2015). Theories of journalism in a digital age. Digital Journalism, 3(1), 1-18.

Steensen, S., Larsen, A. M. G., Hågvar, Y. B., \& Fonn, B. K. (2019). What does digital journalism studies look like? Digital Journalism, 7(3), 320-342.

Swart, J., Peters, C., \& Broersma, M. (2019). Sharing and discussing news in private social media groups. Digital Journalism, 7(2), 187-205.

Wahl-Jorgensen, K. (2019). The challenge of local news provision. Journalism, 20(1), 163-166.
Wahl-Jorgensen, K., \& Hanitzsch, T. (2009). Introduction: On why and how we should do journalism studies. In K. Wahl-Jorgensen \& T. Hanitzsch (Eds.), The handbook of journalism studies (pp. 3-16). New York, NY: Routledge.

Wenzel, A. (2019). Public media and marginalized publics. Digital Journalism, 7(1), 146-163.

Westlund, O., \& Ekström, M. (2018). News and participation through and beyond proprietary platforms in an age of social media. Media and Communication, 6(4), 1-10.

Ziegele, M. (2019). Reader commenting. In T. P. Vos, F. Hanusch, D. Dimitrakopoulou, M. Geertsema-Sligh, \& A. Sehl (Eds.), The international encyclopedia of journalism studies (pp. 1367-1374). Hoboken, NJ: WileyBlackwell.

\section{About the Author}

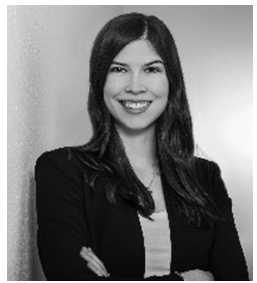

Katherine M. Engelke studied Communication Science and Political Science at the University of Münster and completed her PhD in Communication Science in 2017. She works as a Research Associate at the Department of Communication at the University of Münster. Her expertise is in journalism research with a specific focus on participatory journalism. She also specializes in the emergence and effects of public communication, trust research, political communication, and crises in media. Photo credit: Roland Berg. 


\section{Appendix}

Table A1. 42 publications drawn upon for scoping study.

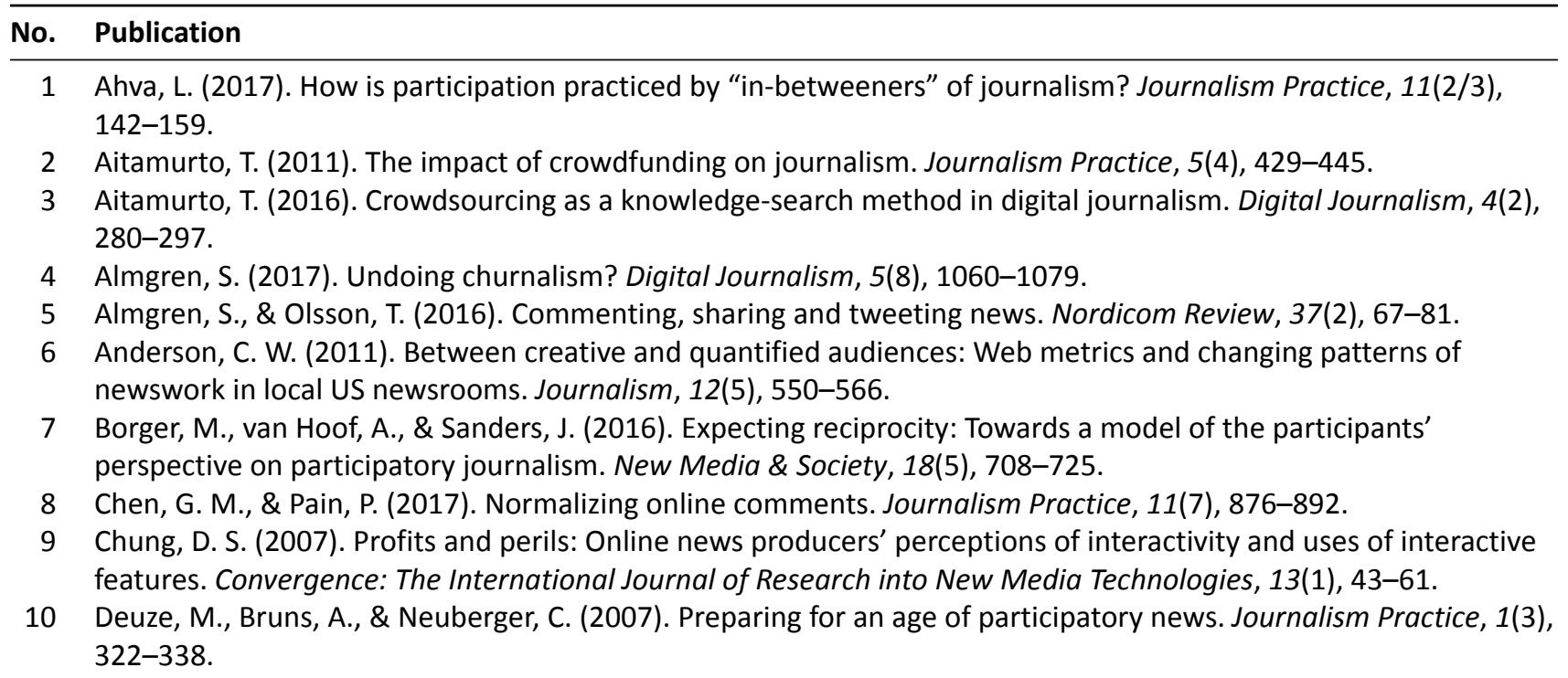

11 Domingo, D., Quandt, T., Heinonen, A., Paulussen, S., Singer, J. B., \& Vujnovic, M. (2008). Participatory journalism practices in the media and beyond. Journalism Practice, 2(3), 326-342.

12 Ferrer-Conill, R., \& Tandoc, E. C. (2018). The audience-oriented editor. Digital Journalism, 6(4), 436-453.

13 Goh, D., Ling, R., Huang, L., \& Liew, D. (2019). News sharing as reciprocal exchanges in social cohesion maintenance. Information, Communication \& Society, 22(8), 1128-1144.

14 Graham, T., \& Wright, S. (2015). A tale of two stories from "below the line": Comment fields at the Guardian. The International Journal of Press/Politics, 20(3), 317-338.

15 Hänska-Ahy, M. T., \& Shapour, R. (2013). Who's reporting the protests? Converging practices of citizen journalists and two BBC World Service newsrooms, from Iran's election protests to the Arab uprisings. Journalism Studies, 14(1), 29-45.

16 Heise, N., Loosen, W., Reimer, J., \& Schmidt, J.-H. (2014). Including the audience. Journalism Studies, 15(4), 411-430.

17 Hellmueller, L., \& Li, Y. (2015). Contest over content. Journalism Practice, 9(5), 617-633.

18 Hermida, A., Fletcher, F., Korell, D., \& Logan, D. (2012). Share, like, recommend. Journalism Studies, 13(5/6), 815-824.

19 Hille, S., \& Bakker, P. (2014). Engaging the social news user. Journalism Practice, 8(5), 563-572.

20 Holton, A. E., Lewis, S. C., \& Coddington, M. (2016). Interacting with audiences. Journalism Studies, 17(7), 849-859.

21 Jian, L., \& Usher, N. (2014). Crowd-funded journalism. Journal of Computer-Mediated Communication, 19(2), 155-170.

22 Jönsson, A. M., \& Örnebring, H. (2011). User-generated content and the news. Journalism Practice, 5(2), $127-144$.

23 Karlsson, M. (2011). Flourishing but restrained. Journalism Practice, 5(1), 68-84.

24 Karlsson, M., Bergström, A., Clerwall, C., \& Fast, K. (2015). Participatory journalism-The (r)evolution that wasn't. Content and user behavior in Sweden 2007-2013. Journal of Computer-Mediated Communication, 20(3), $295-311$.

25 Karlsson, M., Clerwall, C., \& Nord, L. (2018). The public doesn't miss the public. Views from the people: Why news by the people? Journalism, 19(5), 577-594.

26 Ksiazek, T. B., Peer, L., \& Lessard, K. (2016). User engagement with online news: Conceptualizing interactivity and exploring the relationship between online news videos and user comments. New Media \& Society, 18(3), 502-520.

27 Ksiazek, T. B., Peer, L., \& Zivic, A. (2015). Discussing the news. Digital Journalism, 3(6), 850-870.

28 Larsson, A. O. (2018). Diversifying likes. Journalism Practice, 12(3), 326-343.

29 Lawrence, R. G., Radcliffe, D., \& Schmidt, T. R. (2018). Practicing engagement. Journalism Practice, 12(10), 1220-1240.

30 Loosen, W., Häring, M., Kurtanović, Z., Merten, L., Reimer, J., van Roessel, L., \& Maalej, W. (2017). Making sense of user comments. Studies in Communication and Media, 6(4), 333-364.

31 McElroy, K. (2013). Where old (gatekeepers) meets new (media): Herding reader comments into print. Journalism Practice, $7(6), 755-771$. 
Table A1. (Cont.) 42 publications drawn upon for scoping study.

\section{No. Publication}

32 Netzer, Y., Tenenboim-Weinblatt, K., \& Shifman, L. (2014). The construction of participation in news websites. Journalism Studies, 15(5), 619-631.

33 Paulussen, S., \& Ugille, P. (2008). User generated content in the newsroom: Professional and organisational constraints on participatory journalism. Westminster Papers in Communication and Culture, 5(2), $24-41$.

34 Porlezza, C., \& Splendore, S. (2016). Accountability and transparency of entrepreneurial journalism. Journalism Practice, 10(2), 196-216.

35 Scott, J., Millard, D., \& Leonard, P. (2015). Citizen participation in news. Digital Journalism, 3(5), 737-758.

36 Singer, J. B. (2009). Discourse about the 2007 Scottish elections on a national newspaper web site. International Journal of Press/Politics, 14(4), 477-496.

37 Springer, N., Engelmann, I., \& Pfaffinger, C. (2015). User comments: Motives and inhibitors to write and read. Information, Communication \& Society, 18(7), 798-815.

38 Swart, J., Peters, C., \& Broersma, M. (2019). Sharing and discussing news in private social media groups. Digital Journalism, 7(2), 187-205.

39 Tandoc, E. C. (2014). Journalism is twerking? How web analytics is changing the process of gatekeeping. New Media \& Society, 16(4), 559-575.

40 Thurman, N. (2008). Forums for citizen journalists? Adoption of user generated content initiatives by online news media. New Media \& Society, 10(1), 139-157.

$41 \mathrm{Vu}, \mathrm{H}$. T. (2014). The online audience as gatekeeper: The influence of reader metrics on news editorial selection. Journalism, 15(8), 1094-1110.

42 Zamith, R. (2018). On metrics-driven homepages. Journalism Studies, 19(8), 1116-1137. 